\title{
Una visión crítica del desarrollo de la seguridad social y de la legitimación de la desigualdad en México
}

\author{
A critical view of the development of social security \\ and the legitimation of inequality in Mexico
}

\author{
Claudia Agostoni ${ }^{i}$ \\ i Investigadora, Instituto de Investigaciones Históricas/Universidad Nacional Autónoma de México. \\ Ciudad de México - México \\ orcid.org/0000-0001-9186-3028 \\ agostoni@unam.mx
}

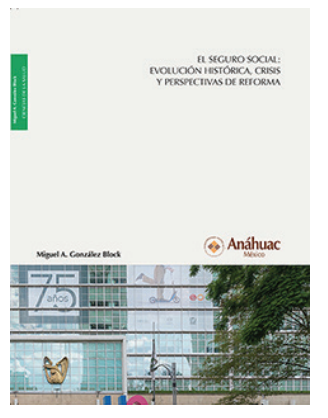

GONZÁLEZ BLOCK,

Miguel Ángel. El seguro social: evolución histórica, crisis y perspectivas de reforma. Huixquilucan del Degollado: Universidad Anáhuac México Norte. 2018. 94p.
El libro de Miguel Ángel González Block (2018) es un estudio crítico y propositivo, con un sólido sustento teórico e histórico, que analiza con detenimiento las múltiples causas de las problemáticas, rezagos, desigualdad y desafíos a los que se enfrenta la seguridad social en México. Para realizar lo anterior, el libro está organizado a partir de una serie de preguntas clave, entre las que destacan las siguientes: el seguro social ¿fue una conquista de los trabajadores? ¿Se trató de una respuesta a las necesidades de desarrollo? ¿Se puede realmente hablar de seguridad social? ¿Proporciona protección de la cuna a la tumba? ¿Tiene un gasto eficiente? ¿Finanzas sanas? ¿Es equitativo? Las respuestas a esas y a otras interrogantes son en todos los casos negativas y se sustentan en un detallado y riguroso análisis de los orígenes, retos, desafíos y problemas políticos, económicos e institucionales que formaron y que forman parte de la seguridad social en el país. Además, González Block enuncia una serie de posibles reformas para evitar que la seguridad social continúe perpetuando una protección social crecientemente estratificada, fragmentada e ineficaz.

El autor examina los antecedentes y primeros años de la seguridad social en México, temáticas que no obstante su importancia han sido motivo de escazas investigaciones históricas recientes. Inicia con un análisis de los antecedentes internacionales y nacionales que entre 1870 a 1929 definieron los derroteros que los sistemas de seguridad social adoptarían en diferentes partes del mundo; presta atención al impacto que durante esos años tuvieron las guerras y las revoluciones, al ascenso de la llamada "cuestión social", a la multiplicación de huelgas, movilizaciones y paros laborales, al igual que al creciente reconocimiento que adquirió garantizar la salud de los trabajadores a nivel mundial. Y es precisamente en ese contexto, marcado por las presiones del incipiente movimiento obrero, por las demandas y debates en torno a la necesidad de que el Estado interviniera en la mejora de las condiciones 
de vida, de trabajo y de salud de amplios sectores sociales, al igual que debido a los principios de justicia social y del derecho a la salud consignados en la Constitución Política de los Estados Unidos Mexicanos (1917), que González Block se adentra en el estudio de cómo en México el reconocimiento de esos derechos fue desde un inicio desigual. Por ello destaca que el tránsito del reconocimiento de esos derechos de un plano discursivo a un puntual y preciso marco legal e institucional, fue paulatino, desigual e intensamente combatido por diferentes sectores sociales, hasta por lo menos la década de 1940.

González Block también centra su atención en cómo, durante 1943, al promulgarse la Ley del Seguro Social, la oposición no se dejó esperar: obreros, patrones, aseguradoras y organizaciones médicas se negaron, por motivos económicos, por estar en desacuerdo con lo establecido en los contratos colectivos, por considerase que los médicos pasarían a ser asalariados del Estado o, bien, debido a que los profesionales de la medicina fueron excluidos del Consejo Técnico del IMSS y de la toma de decisiones, entre otros elementos. Asimismo, destaca que la formulación del Seguro Social "de manera autónoma por el Estado se apoyó en la tecnoburocracia, en el corporativismo autoritario" (González Block, 2018, p.34) y en la exclusión de amplios sectores sociales, por lo que únicamente el $11.6 \%$ de la población económicamente activa en el sector formal recibió algún tipo de cobertura en ese momento, excluyéndose a los trabajadores del campo. Y es precisamente la exclusión uno de los ejes centrales de este estudio; exclusión que procuró ser diluida apelándose a discursos "revolucionarios" y nacionalistas, y al reiterarse una y otra vez una promesa: con el tiempo, la mayor parte de la población sí se beneficiaría del derecho a la seguridad social. Sin embargo, en la actualidad y a 74 años de distancia de la promulgación de la Ley del Seguro Social, la mayor parte de la población prosigue esperando el cumplimiento de esa promesa, y con ello, el derecho a formar parte de un sistema que garantice estándares mínimos de bienestar a lo largo de sus ciclos de vida.

Aunado a lo anteriormente expuesto, González Block detalla las múltiples contradicciones entre el reconocimiento discursivo del derecho a la salud de todos los mexicanos y lo que paulatinamente sí se implementó: un sistema de seguridad social profundamente desigual y subordinado al Estado. Estudia las múltiples reformas por las que ha atravesado la Ley del Seguro Social y destaca cómo las reformas posibilitaron una reconceptualización de la desigualdad "pasando del enfoque en grupos laborales con menos capacidades en el origen a su conceptualizacion como grupos laborales 'marginados' con Luis Echeverría" (19701976) y a "poblaciones marginadas" con López Portillo (1976-1982) (González Block, 2018, p.44). También se estudia con detenimiento cómo hasta 2018 el IMSS ofrecía 15 categorías de aseguramiento diferenciados y heterogéneos según reglas de contribución, de acceso a servicios y de infraestructura, prohibiéndose la elección de los prestadores de servicios de acuerdo con las preferencias y la confianza de los asegurados, lo cual ha inhibido la oferta, la innovación, la eficiencia, la atención continua, al igual que la prevención y la atención de largo aliento de los riesgos laborales. Por tanto, la fragmentación y la duplicidad o superposición de servicios, la implementación de mecanismos de protección diferenciada y la dotación de paliativos temporales para una población que cada vez se enfrenta a una más intensa rotación laboral, han derivado en el debilitamiento de los principios fundamentales de la seguridad social y en la renuncia del compromiso de las instituciones con el bienestar de los ciudadanos. 
En suma, González Block presenta un estudio claro y detallado de la fragmentada y crecientemente desigual afiliación de la población a la seguridad social, de los graves problemas de desfinanciamiento, de la multiplicidad de categorías de aseguramiento, prestaciones, regímenes y esquemas y de la creciente duplicidad de servicios. Destaca la centralidad que reviste generar herramientas que permitan la solvencia financiera de los seguros sociales para contener y evitar el avance de la inseguridad social, y remarca la importancia que tiene establecer mecanismos sólidos y permanentes que garanticen la atención y la confianza entre el público, los servicios y los prestadores de salud.

\section{REFERENCIA}

GONZÁLEZ BLOCK, Miguel Ángel.

El seguro social: evolución histórica, crisis y perspectivas de reforma. Ciudad de México:

Universidad Anáhuac México. E-book.

Disponible en: $<\mathrm{http}$ ://pegaso.anahuac.mx/

accesoabierto/publicaciones.php >. Acceso en: 22

ene. 2020. 2018. 